\title{
Spatial distribution of visual attention: Perceptual sensitivity and response latency
}

\author{
TODD C. HANDY \\ University of Califormia, Davis, California \\ ALAN KINGSTONE \\ University of Alberta, Edmonton, Alberta, Canada \\ and \\ GEORGE R. MANGUN \\ University of California, Davis, California
}

\begin{abstract}
Studies of the spatial distribution of visual attention have shown that attentional facilitation monotonically decreases in a graded fashion with increasing distance from an attended location. However, reaction time (RT) measures have typically shown broader gradients than have signal detection (SD) measures of perceptual sensitivity. It is not clear whether these differences have arisen because the stages of information processing indexed by RT measures are different from those indexed by SD measures, or whether these differences are due to methodological confounds in the SD studies. In the present set of experiments, the spatial distribution of attention was studied by using a luminance detection task in an endogenous cuing paradigm that was designed to permit accurate calculations of SD and RT measures for targets at cued and uncued locations. Subjects made target-present/absent decisions at one of six possible cued or uncued upper visual hemifield locations on each trial. The results from three experiments suggest that the differences between broad and focal attentional distributions are not the result of different stages of information processing indexed by RT measures as opposed to SD measures. Rather, the differing distributions appear to reflect variations in attentional allocation strategies induced by the perceptual requirements typical of RT paradigms as opposed to SD paradigms. These findings support numerous prior studies showing that spatial attention affects perceptual sensitivity and that the strategic allocation of attention is a highly flexible process.
\end{abstract}

It has been well established that precuing covert spatial attention to a specific location in the visual field facilitates response performance for stimuli appearing at the cued location. Many studies have shown, for example, that reaction time (RT) is faster for events occurring at an attended spatial region than for events occurring at an unattended spatial region (e.g., Posner, 1978, 1980; Posner, Snyder, \& Davidson, 1980; Shulman, Sheehy, \& Wilson, 1986; Shulman, Wilson, \& Sheehy, 1985; see Klein, Kingstone, \& Pontefract, 1992, for a recent review). Spatial attention has also been shown to improve detection and discrimination accuracy for events at attended as

The authors are grateful to Rob Egly, Ray Klein, Amishi Jha, and Mado Proverbio for helpful discussions on portions of this work, and to Mike Gazzaniga and Steve Hillyard for advice and support. We also thank Steve Luck, Jon Hansen, and Clif Kussmaul for their assistance, and to Art Kramer, Hermann Müller, and two anonymous reviewers for helpful comments on an early version of this manuscript. The data from Experiment 1 were originally presented at the inaugural meeting of the Cognitive Neuroscience Society, San Francisco, March, 1994. This research was supported by grants from NIMH, NIH, HFSPO, and by the McDonnell-Pew Program in Cognitive Neuroscience at UC Davis. Correspondence concerning this article should be addressed to G. R. Mangun, Center for Neuroscience, University of California, Davis, CA95616 (e-mail: grmangun@ucdavis.edu). opposed to unattended locations (e.g., Bashinski \& Bacharach, 1980; Downing, 1988; Hawkins et al., 1990; Heinze \& Mangun, 1995; Luck et al., 1994; Mangun \& Hillyard, 1988; Müller \& Humphreys, 1991).

How attention is distributed across the visual field when directed to a single location is an important issue in attention research. Using a cuing paradigm, Downing and Pinker (1985) showed that for luminance-onset targets, response latency increased monotonically with increasing target distance from the cued visual field location. A broadly graded pattern of this type was also described by Shulman et al. (1985) for luminance detection following attentional orienting to the visual field location of a nonfoveal cue. These and similar findings (see below) have led to the "gradient" hypothesis, which proposes that the effects of attention on response performance decline with increasing distance from the attended location. This conceptualization of an attentional gradient has received much support (Andersen, 1990; Andersen \& Kramer, 1993; Egly \& Homa, 1991; Henderson, 1991; Henderson \& Macquistan, 1993; Klein \& McCormick, 1989; LaBerge \& Brown, 1989; Mangun \& Hillyard 1987, 1988).

Attentional gradients as measured by RT have been observed in a variety of experimental designs. In cuing studies, gradient-like patterns have been observed during 
both endogenous and exogenous attentional orienting (e.g., Downing \& Pinker, 1985; Henderson \& Macquistan, 1993). A response competition paradigm was employed by Eriksen and St. James (1986), who found that RT decreased with increasing distance between a target and competing noise stimulus. Similarly, a graded RT pattern was reported by LaBerge (1983) for subjects detecting a probe digit when categorizing the middle letter of five-letter word or nonword strings. Gradient-like patterns have also appeared in the results of studies that do not specifically address the spatial distribution of attention issue (e.g., Miller, 1991; Pan \& Eriksen, 1993; Shepherd \& Müller, 1989; Tassinari, Aglioti, Chelazzi, Marzi, \& Berlucchi, 1987; Tsal, 1983).

Attentional gradients have been observed to span both small and large spatial regions. Using a spatially compact display, LaBerge (1983) observed that a gradient pattern in RT could be obtained for targets that were within $1^{\circ}$ of the attended location. Using a very broad display, Henderson and Macquistan (1993) found a gradient in RT across uncued locations extending out to $19.7^{\circ}$ from a peripherally cued location. Other studies have typically yielded RT gradients across spatial regions between these extremes (e.g., Downing \& Pinker, 1985; Henderson, 1991; LaBerge \& Brown, 1986, 1989; Shulman et al., 1986; Shulman et al., 1985). Recent studies by Andersen using response-compatibility paradigms (1990; Andersen \& Kramer, 1993) have shown that these gradients can exist within three-dimensional space. A feature common in all of these reports is that RT gradients decline continually with increasing distance from the cued/attended region, only showing a tendency to plateau or approach asymptote at very large cue-target distances $\left(20^{\circ}+\right.$; Shepherd \& Müller, 1989).

In contrast to studies that measure response latency, some investigations of the spatial distribution of attention have employed methods derived from signal detection (SD) theory, thereby allowing for the calculation of $d^{\prime}$ and $P(A)$ (SD measures of response accuracy; see Green \& Swets, 1966). For example, Mangun and Hillyard (1988) found that target detectability, as indexed by $d^{\prime}$, was highest at an attended location and showed a graded decrease with increasing distance from the attended location. However, $d^{\prime}$ was only a secondary measure in their electrophysiological study, and their experimental design required sustained (i.e., blocked) attention to rapid sequences of stimuli. Thus, it is difficult to compare their results directly with those of trial-by-trial cuing studies.

Downing (1988) investigated the spatial distribution of attention in an endogenous cuing paradigm, using a circular, 12-location display. She measured $d^{\prime}$ in four different task conditions: luminance detection, and discrimination of brightness, orientation, and form. On each trial, from zero to four targets could be present. Following posttarget masking at all 12 locations, 4 locations were probed for a target-present/absent decision. Any location actually receiving a target was always probed. As in RT studies, Downing found decreases in $d^{\prime}$ with increasing target distance from the attended location. However, in all four task conditions the $d^{\prime}$ distributions showed a large initial drop, with relatively little change in $d^{\prime}$ beyond about $3^{\circ}$ from the attended location.

Using methodology similar to Downing's (1988), Müller and Humphreys (1991) measured both $d^{\prime}$ and $P(A)$ in a luminance-increment detection task with fourand eight-location circular displays. Although the primary focus of their study was to investigate whether spatial cuing influenced perceptual sensitivity, they also addressed the gradient issue. They reported gradient patterns in both endogenous and exogenous cuing conditions that showed, as in Downing's study, large initial drop-offs in $d^{\prime}$ and $P(A)$, with little relative change in either measure beyond about $3^{\circ}$ from the attended location.

These relatively focal attentional distributions obtained with SD methods appear to differ from the broader RT distributions obtained with RT methods. This observation may indicate that RT and SD measures index different aspects of attention-modulated visual information processing. For example, $d^{\prime}$ and $P(A)$ have frequently been understood to provide an index of relatively early perceptual-level processes such as the sensory encoding and perceptual analysis of stimulus information (e.g., Bashinski \& Bacharach, 1980; Luck et al., 1994), whereas RT has been understood to reflect both early perceptual processes and later decision and/or response related operations (e.g., Santee \& Egeth, 1982). Accordingly, attention-based modulations in RT might reflect the inclusion of later, decision/response-related processing components in addition to (or independent of) the perceptual-level effects of spatial attention that are presumably indexed by SD measures. Indeed, such a view has been the focus of a long debate about the stages of processing involved in attentional selection (see, e.g., Hawkins et al., 1990; Müller \& Findlay, 1987; Shaw, 1984; Sperling, 1984; Sperling \& Dosher, 1986; see also Shiu \& Pashler, 1994).

Although RT and SD measures may, in fact, index different aspects of attention-related processing, thereby offering an explanation for the differences between RT and SD gradients, some recently formulated methodological concerns raise doubts about the accuracy of the attentional distributions in Downing's (1988) and Müller \& Humphreys's (1991) studies. Specifically, Hawkins et al. (1990) pointed out two problems relevant to the methodology of both studies. First, targets were more likely at their cued locations than at their uncued locations. As a result, if subjects were uncertain about target locations, they may have localized targets preferentially to the cued location because of the greater target probability at that location than at the uncued locations (.80 vs. .50$)$. This tendency would introduce systematic distortions in the SD scores calculated for attended and unattended locations. Second, in both studies, subjects were required to report on multiple target events on each trial. As a result, differences may have arisen in memory retention of target information (e.g., target location) between cued and uncued target locations.

To correct for these problems, Hawkins et al. (1990) modified Downing's (1988) postmask probe technique 
by equalizing target-present/absent probabilities at all locations and probing only one location per trial. With these modifications of Downing's original paradigm, difficulties arising from multiple probe locations and unequal target probabilities were eliminated. However, Luck et al. (1994) recently pointed out additional concerns about memory storage strategies arising from the brief delay that Hawkins et al. (1990) inserted between mask and probe onsets. Specifically, this delay may have caused subjects to preferentially maintain or rehearse information from the cued location. Accordingly, Luck et al. further modified the Hawkins et al paradigm by using only one mask, which also served as the probe, thereby eliminating the mask-probe delay.

Together, Hawkins et al. (1990) and Luck et al. (1994) provided behavioral and electrophysiological evidence showing attentional modulations of early perceptuallevel processing. However, their findings do not address the issue of how attention is spatially distributed. In Experiment 1, presented below, we used their improved SD methodology to investigate how attention drops off with increasing distance from an attended location. Both RT and SD measures were obtained to allow a direct comparison of the attentional distributions reflected by each.

\section{EXPERIMENT 1}

Experiment 1 was designed to investigate how spatial attention is distributed across the visual field when attention has been voluntarily oriented to a discrete spatial location. In a luminance-detection task, subjects were required to make a forced two-choice decision regarding the presence or absence of a threshold-level target stimulus that could occur at one of six possible locations in the upper visual hemifield. A posttarget mask also served as a probe to indicate the location at which a targetpresent/absent decision had to be made. This paradigm was similar to that used by both Downing (1988) and Müller \& Humphreys (1991), with modifications to avoid possible confounds related to target localization, memory decay, and preferential maintenance/rehearsal of cued location information (Hawkins et al., 1990; Luck et al., 1994). RT and $A^{\prime}$ were measured for target detections at each spatial location in all possible combinations of attended and unattended conditions. $A^{\prime}$ is an estimate of $P(A)$ used when only a single pair of hit and false alarm (FA) rates are obtained for each cue-target condition (Craig, 1979; Pollack \& Norman, 1964). $A^{\prime}$ was preferred to $d^{\prime}$ because, unlike $d^{\prime}$, it is a nonparametric measure of perceptual sensitivity and thus avoids the possible distortions that might occur in $d^{\prime}$ calculations if assumptions regarding the normal distributions of signal and noise were violated.

\section{Method}

Subjects. Sixteen members of the University of California, Davis community between the ages of 18 and 31 ( 9 females, 7 males) served as paid participants. All were right-handed and had normal or corrected-to-normal vision. Three additional subjects were excluded because of frequent, systematic eye movements during testing.

Apparatus and Stimuli. The stimuli were presented on an Apple Macintosh II microcomputer color monitor placed $100 \mathrm{~cm}$ from the subject. Each trial consisted of the presentation of a cue (either an arrow or a square neutral cue) followed by a small, thresholdlevel target (on $50 \%$ of the trials) and a mask (on $100 \%$ of the trials; see Figure 1). The target stimulus was a white rectangle that ranged in size from one to six pixels. The mask consisted of a set of randomly oriented lines of various lengths, $0.01^{\circ}-0.3^{\circ}$ thick, arranged within a $1.5^{\circ}$ square. The spatial cue was a pink arrow $0.6^{\circ}$ long. The neutral cue was a pink $0.3^{\circ}$ filled square. Both cues were framed by an eight-sided pink polygon outline $\left(0.8^{\circ}\right.$ tall $\times 0.9^{\circ}$ wide). All stimuli were presented against a darkened monitor screen that contained the standing background display described below.

There were six possible locations where the target and mask stimuli could appear (Figure 2). These six locations were located in the upper visual field, $6.0^{\circ}$ from fixation, along an imaginary semicircle. Each stimulus location was demarcated by a $1.5^{\circ}$ red outline square that was centered on the imaginary semicircle. The boxes were equally spaced, $2.5^{\circ}$ center-to-center, with the center of the two most lateral boxes positioned $2.7^{\circ}$ above the horizontal meridian. Thus, the stimulus display was symmetric about the vertical meridian, with three stimulus locations in each visual hemifield. Along with a four-pixel square pink fixation spot, these six boxes formed a constant background for the duration of each block of trials. Both the arrow and neutral cues were presented at fixation.

Electro-oculograms (EOGs) were recorded from three sites, amplified with a gain of 50,000 , band-pass filtered from .01 to $100 \mathrm{~Hz}$, and digitized at $200 \mathrm{~Hz}$. These included a horizontal EOG that was recorded from the right outer canthus, a vertical EOG recorded inferior to the right eye, and an oblique EOG recorded from a site on the right supraorbital ridge at a $45^{\circ}$ angle relative to both the horizontal and vertical axes of the eye. All electrodes were referenced to the left mastoid. On-line monitoring of the EOGs was used to control for large eye movements by providing feedback to the subject by the investigator. Off line, trials were rejected that contained eye movements or blinks, and subsequent signal averaging to the onset of the cue stimuli allowed for the detection of very small $\left(<0,36^{\circ}\right)$ systematic eye movements (see Mangun \& Hillyard, 1991, Experiment 4). On the average, only about $1 \%-2 \%$ of each subject's total number of trials were rejected for eye movement or blink artifacts. On the basis of the averaged EOG signals, three subjects were disqualified and replaced, as noted above.

Procedure. Subjects made a forced two-choice decision regarding the presence or absence of the target stimulus. The subjects responded by pressing the appropriate microswitch ("yes" with one thumb, "no" with the other thumb, counterbalanced between subjects) located on a hand-held response pad. The subjects were instructed to maintain fixation on the fixation spot for the duration of each trial block. If an arrow cue was presented, the subjects were instructed to shift their attention (but not their eyes) to the box indicated by the arrow, this being the location at which a targetpresent/absent decision would most likely be required. No specific directions were given on how the subjects should orient their attention when presented with the neutral cue, although they were told that all locations were equally likely to be masked/probed.

Cue duration was $150 \mathrm{msec}$, and the cue-to-target stimulus onset asynchrony (SOA) varied randomly between 245 and $660 \mathrm{msec}$ (rectangular distribution). On target-present trials, the target was flashed for $60 \mathrm{msec}$ in one of the six locations. The mask/probe was presented for $105 \mathrm{msec}$, beginning at target offset. On targetabsent trials, the mask/probe was presented for $105 \mathrm{msec}$ following a randomly varied cue-mask SOA of $305-720 \mathrm{msec}$. On all trials, subjects made a target-present/absent decision at the location of the mask/probe. The next trial began $1,400 \mathrm{msec}$ after the onset of the mask/probe. Trials in which a response occurred less than $200 \mathrm{msec}$ after onset of the mask/probe were discarded. Trials with 
Cue

(150 msec)
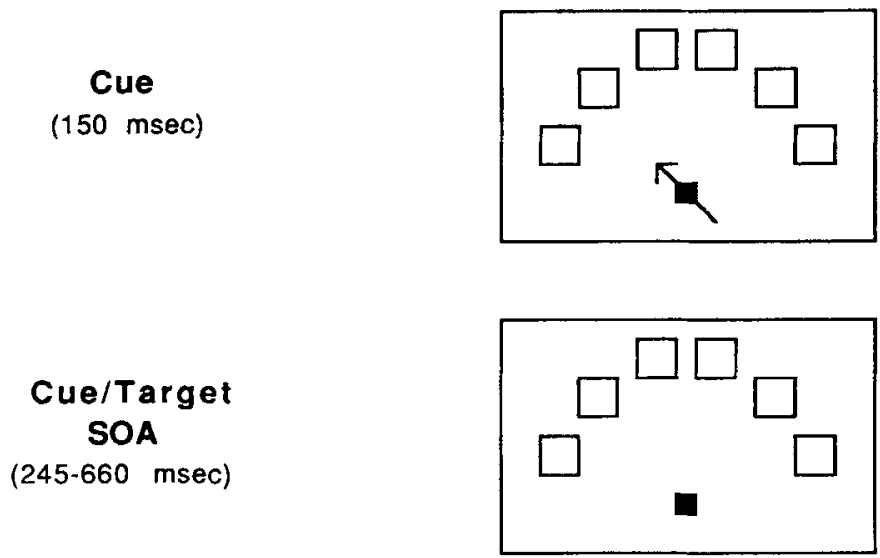

Target/

No Target

(60 msec)

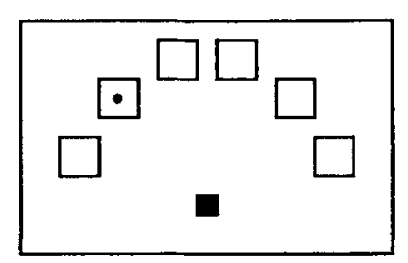

$(50 \%)$

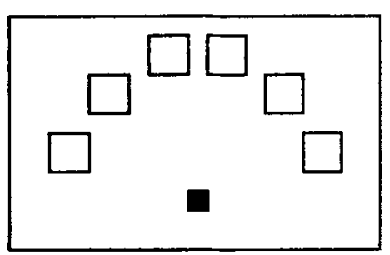

$(50 \%)$

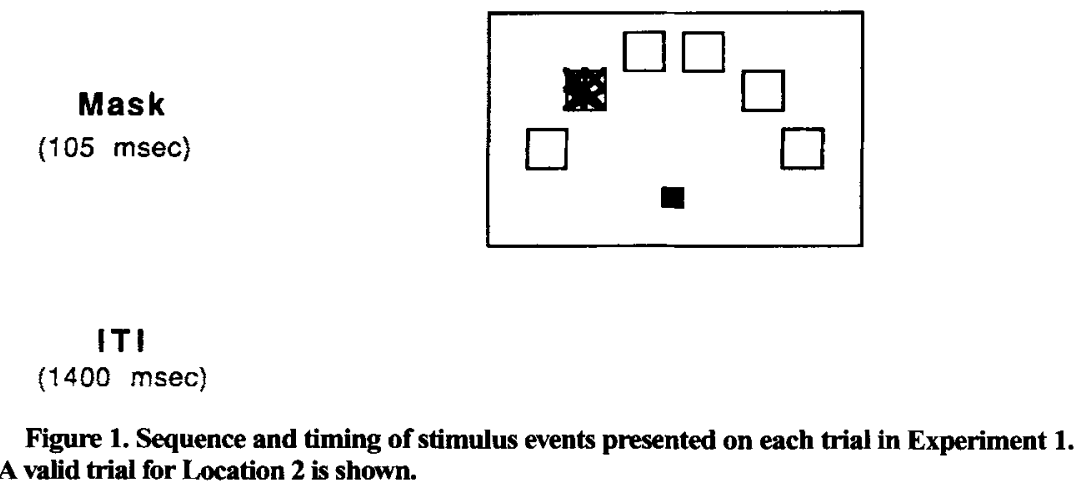

Mask

(105 msec) response latencies greater than $1,400 \mathrm{msec}$ were discarded, along with the subsequent trial. Although RTs were extracted from the data, no emphasis was given to response latency during instruction. Each experimental block consisted of 63 trials and lasted slightly over $2 \mathrm{~min}$.

Cue probabilities were as follows: The arrow cue occurred with an overall .81 probability. On these trials, the mask/probe occurred at the cued location (a "valid" trial), with .71 probability, and at each of the five noncued locations (an "invalid" trial), with .058 probability. On neutral cue trials (.19 overall probability), the mask/probe occurred at each of the six locations with .167 probability. The target was present across all conditions and locations with .50 probability.

Subjects were tested in three 2 -h sessions, with each session occurring on separate days. At the beginning of the first session, the subjects were given extensive practice in the task until near-perfect performance was established with a relatively large, easy-to-detect target. The size of the target was then reduced on successive practice blocks until the subject's performance dropped to approximately $75 \%$ correct, collapsed across hits (a target-present response on target-present trials) and correct rejections (a target-absent response on target-absent trials). This performance level was chosen to minimize the possibility of floor or ceiling effects. The target size was also adjusted as was necessary between blocks to maintain this performance level. Sessions 2 and 3 were run in a similar fashion, although less practice was required prior to data collection. In addition to practice blocks, approximately 12 test blocks were run in Session 1; 20 test blocks were run in both Session 2 and Session 3.

\section{Results}

Data analysis. Attentional distributions as reflected by RT and $A^{\prime}$ measures were generated by holding the masked/probed location constant and varying the cued (attended) location. This means that a distribution was generated for each display location. Given the six display locations in the experiment, six different distributions were obtained for both $A^{\prime}$ and RT (see Table 1). Each distribution had one valid score (attention cued to the location probed) and five invalid scores (attention cued to one of the five locations not probed). ${ }^{1}$

Because the experimental display was symmetric about the vertical meridian (see Figure 2), visual field 


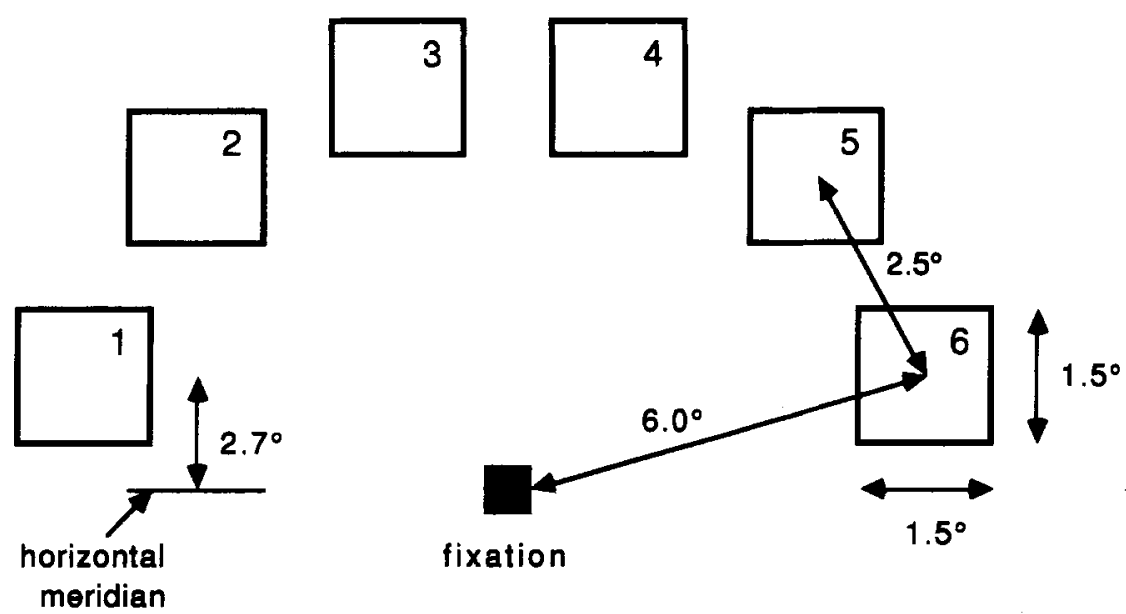

\begin{abstract}
Figure 2. Spatial arrangement of stimulus display used in all three experiments. Reaction time and $A^{\prime}$ distributions are defined in the text according to display location, indicated by the number in the upper right-hand corner of each box. These numbers were not included in the actual experimental display.
\end{abstract}

was included as a factor in the initial analyses in order to test for possible hemispheric asymmetries involved in the allocation of visual attention (see, e.g., Mangun et al, 1994; Previc \& Blume, 1993; Reuter-Lorenz, Kinsbourne, \& Moscovitch, 1990; Tsal, 1989). The results of these visual field analyses are reported below. For simplicity of presentation, however, the data shown in the figures below are collapsed across symmetric locations in the two visual hemifields (i.e., Locations 1 and 6,2 and 5 , and 3 and 4 ).

Response accuracy. Mean $A^{\prime}$ values are presented in the upper half of Table 1 as a function of cued and probed location. Figure 3 presents the three $A^{\prime}$ distributions that were generated by collapsing across symmetric left and right visual field stimulus locations. The data are plotted as costs and benefits, defined as the decrement (cost) or the improvement (benefit) in performance relative to a neutral (uninformative cue) condition. The dashed line for each distribution indicates the neutral trial mean, demarcating the crossover from benefits (above) to costs (below). Two main trends emerge: First, there were effects of spatial attention on detection accuracy, with $A^{\prime}$ being highest when a cued location was probed. Second, in general, the distributions approach asymptote within $2.5^{\circ}$ of the attentional locus, although the $2 / 5$ distribution may be slightly less focal (but see below). These observations were confirmed statistically.

To investigate overall cuing and visual field effects, three omnibus repeated-measures multivariate analyses of variance (MANOVAs) were conducted on the $A^{\prime}$ distributions in Table 1, one for each symmetric left-right distribution pair (i.e., Locations 1 and 6, 2 and 5, and 3 and 4). There were two within-subjects factors, attention location (six levels) and visual field (two levels). For all comparisons there was a significant main effect of attention location [all $F_{s}(5,70)>2.48$, all $p s<.04$ ]. A significant main effect of visual field was found in the Probe
$1 / 6$ comparison $[F(1,14)=16.22, p=.001]$; this was due to more accurate performance overall in the Probe 6 versus Probe 1 distribution. However, this effect did not interact with attention location.

In order to determine whether the significant attention effects were restricted only to the valid location, a second set of repeated-measures MANOVAs were conducted that were identical to those above, except that they excluded the valid score in each distribution (i.e., attention location was now a factor with five levels). A significant main effect of attention was found only for the Probe $2 / 5$ distributions $[F(4,56)=3.55, p=.012]$. This appeared to be the result of the relatively high $A^{\prime}$ s for the two invalid scores averaged together as the invalid

Table 1

Mean $\boldsymbol{A}^{\prime}$ and Reaction Time (RT) Values for Experiment 1, Averaged Across the 16 Subjects

\begin{tabular}{|c|c|c|c|c|c|c|c|}
\hline \multirow{2}{*}{$\begin{array}{l}\text { Probe } \\
\text { Location }\end{array}$} & \multicolumn{6}{|c|}{ Cue Location } & \multirow[b]{2}{*}{ Neutral } \\
\hline & 1 & 2 & 3 & 4 & 5 & 6 & \\
\hline \multicolumn{8}{|c|}{$A^{\prime}$} \\
\hline 1 & .845 & .801 & .796 & .789 & .790 & .746 & .817 \\
\hline 2 & .856 & .857 & .819 & .751 & .789 & .771 & .828 \\
\hline 3 & .772 & .739 & .813 & .787 & .799 & .743 & .792 \\
\hline 4 & .733 & .786 & .706 & .802 & .741 & .744 & .798 \\
\hline 5 & .814 & .791 & .797 & .783 & .845 & .835 & .827 \\
\hline 6 & .868 & .865 & .835 & .877 & .854 & .886 & .853 \\
\hline \multicolumn{8}{|c|}{ RT } \\
\hline 1 & 493 & 579 & 554 & 568 & 558 & 568 & 554 \\
\hline 2 & 556 & 501 & 575 & 572 & 552 & 566 & 557 \\
\hline 3 & 596 & 549 & 510 & 603 & 572 & 602 & 551 \\
\hline 4 & 585 & 545 & 519 & 499 & 556 & 560 & 560 \\
\hline 5 & 593 & 583 & 571 & 536 & 496 & 547 & 538 \\
\hline 6 & 561 & 565 & 560 & 556 & 508 & 467 & 523 \\
\hline
\end{tabular}

Note-Cue and probe location numbers (1-6) correspond to the six display locations used in the experiment, as can be seen in Figure 2. Probe-constant distributions go across rows and attention-constant distributions go down columns (see note 1). 

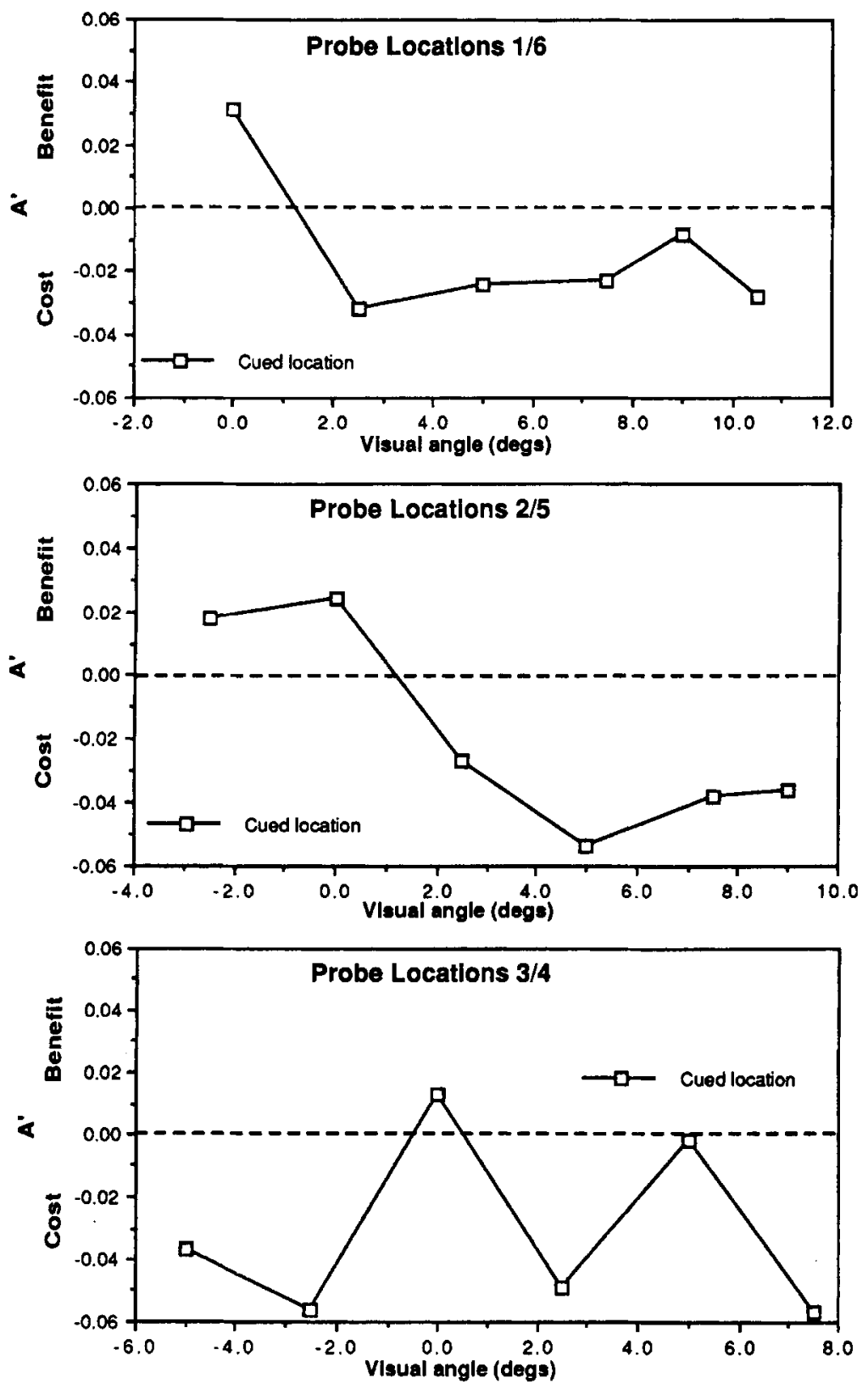

Figure 3. $A^{\prime}$ distributions from Experiment 1 collapsed across each pair of locations symmetric about the vertical meridian. $A^{\prime}$ cost/benefit is plotted as a function of the distance between cued and probed locations. The distance was measured as the shortest line between the center of any two locations. On the horizontal axis, negative visual angles represent cued locations lateral to the probe, positive visual angles represent cued locations medial to the probe, and the validly cued location is represented by a visual angle of $0.0^{\circ}$. In all graphs, the vertical meridian occurs between the three left-most and three right-most locations.

score to the left of the valid score in the middle graph of Figure 3 (see also Table 1). To test this hypothesis, a second repeated-measures MANOVA was performed on the $2 / 5$ distribution that excluded both the valid score and the aforementioned invalid scores (i.e., attention location now was a factor with four levels). The results indicated that these remaining four adjacent invalid scores (i.e., the four invalid scores to the right of the valid score in the middle graph of Figure 3 ) in the Probe $2 / 5$ distributions showed no effect of attention $[F(3,45)=0.61, p=.609]$. There were no significant interactions.

Although attention effects appeared to be isolated to (or near, in the Probe $2 / 5$ distributions) the validly cued location, the rate of change in $A^{\prime}$ with increasing distance from the valid location may not have been large enough to produce a significant result in the statistical tests above. 
Accordingly, in order to maximize the chances of detecting effects of attention, the two invalid scores in each distribution representing the greatest spatial separation between contiguous invalid locations were compared (i.e., the nearest and farthest invalid scores to the right of the valid score in each graph in Figure 3). This third set of repeated-measures MANOVAs, with attention location as a factor (two levels), indicated that there were no significant differences between these two invalid points in each distribution.

Overall, the MANOVA results showed that spatial attention facilitates detection accuracy at an attended location, and that the pattern of these effects for symmetrical locations in the left visual field did not differ from that for the symmetrical locations in the right visual field. This facilitation occurred within $2.5^{\circ}$ of the attended location (the lower resolution limit of our display) and was manifest as a change in detection accuracy $\left(A^{\prime}\right) .^{2}$ Beyond $2.5^{\circ}$, there was no evidence for modulations in detection accuracy.

Reaction times. Mean RT values are presented as a function of cued and probed location in the lower half of Table 1. Figure 4 presents the three RT distributions generated by collapsing across left/right symmetrical locations, as was shown for $A^{\prime}$. The RT distributions approach asymptote within $2.5^{\circ}$ of the attended location. This pattern is somewhat inconsistent with RT distributions reported previously in the literature for cuing studies, which tend to show either no asymptote or asymptotes only at much larger cue-target distances (e.g., Henderson \& Macquistan, 1993; Shepherd \& Müller, 1989; Shulman et al., 1985; Shulman et al., 1985). These observations were confirmed statistically with the same procedures as for $A^{\prime}$.

Three omnibus repeated-measures MANOVAs were conducted with attention location (six levels) and visual field (two levels) as main factors. All three distribution comparisons showed a significant main effect of attention location [all $F \mathrm{~s}(5,70)>7.62$, all $p \mathrm{~s}<.001$ ]. No main effects of visual field or interactions were found.

A second series of repeated-measures MANOVAs, identical to those above except that they excluded the valid scores in each distribution (i.e., attention location was now a factor with five levels), yielded no effects of attention location across the five invalid scores. This suggests that the effects of attention were restricted to within $2.5^{\circ}$ of the valid location. In order to maximize the chances of detecting effects of attention, the two invalid scores in each distribution representing the greatest separation between contiguous invalid locations were compared (i.e., the nearest and farthest invalid location to the right of the valid score in each graph in Figure 3). This third set of repeated-measures MANOVAs (with attention location as a main factor with two levels) indicated that there was a significant effect of location only for the $3 / 4$ distribution $[F(1,14)=4.90, p=.044]$, indicating a tendency for a slightly less focal RT pattern in this distribution. ${ }^{3}$ Nevertheless, overall the results show that spatial attention facilitated RTs to targets at attended locations, and this facilitation was confined to within $2.5^{\circ}$ of the attended location - a pattern similar to that for $A^{\prime}$.

Comparison of $A^{\prime}$ and RT. A comparison of $A^{\prime}$ and RT distributions is shown in Figure 5. In order to facilitate a direct comparison and to allow for statistical analysis, the $A^{\prime}$ and RT data presented in Figure 5 were normalized (see the Appendix). Symmetric distribution pairs were collapsed in the following analyses. Although differences can be seen between distributions in terms of relative costs and benefits, all normalized distributions show a large drop-off within $2.5^{\circ}$ of the attended location and tend to asymptote with increasing cue-target distance. This observation was confirmed statistically.

Three repeated-measures MANOVAs (one for each collapsed distribution pair) with attention location (six levels) and response measure (two levels) as factors showed that there were significant main effects of attention location in each distribution pair [all $F \mathbf{s}(5,75)>$ 8.06 , all $p \mathrm{~s}<.001]$. However, no effects of measure nor any interactions were found, suggesting that the $A^{\prime}$ and RT patterns were similar in each distribution pair.

Although the foregoing analyses indicate a general resemblance in the effects of attention between $A^{\prime}$ and RT, they do not indicate whether statistical differences between distributions across the invalid scores may have been present. To test for this possibility, a second series of repeated-measures MANOVAs were performed, identical to those above except that the valid scores in each distribution were excluded (i.e., attention location was now a factor with five levels). Any differences in the way RT as opposed to $A^{\prime}$ dropped off with increasing distance from the probed location would be manifest as an interaction between response measure and attention location. However, no significant interactions of attention location with response measure were found [all $F \mathrm{~s}(4,60)<$ .99 , all $p \mathrm{~s}>.424$ ], indicating that there were no differences between measures across the invalid locations. Together, these analyses strongly suggest that the $A^{\prime}$ and RT attentional distributions were the same.

\section{Discussion}

Cuing attention to a location in the visual field produced a significant facilitation in $A^{\prime}$ for targets presented to that location, and decrements in detection performance for targets presented elsewhere. Thus, the data provide additional evidence in support of the view that focused visual attention modulates perceptual sensitivity (see, e.g., Downing, 1988; Hawkins et al., 1990; Luck et al., 1994; Müller \& Humphreys, 1991). The spatial distribution of these attention-related modulations extended only $2.5^{\circ}$ from the validly cued locations, the lower limit of our display resolution. Beyond this distance, there was comparatively little effect of attention on response performance. Relatively focal $A^{\prime}$ patterns such as these are consistent with the attentional distributions reported by Downing and by Müller and Humphreys using SD measures. Thus, the focal patterns that they reported were not artifacts of how their SD measures were calculated. 

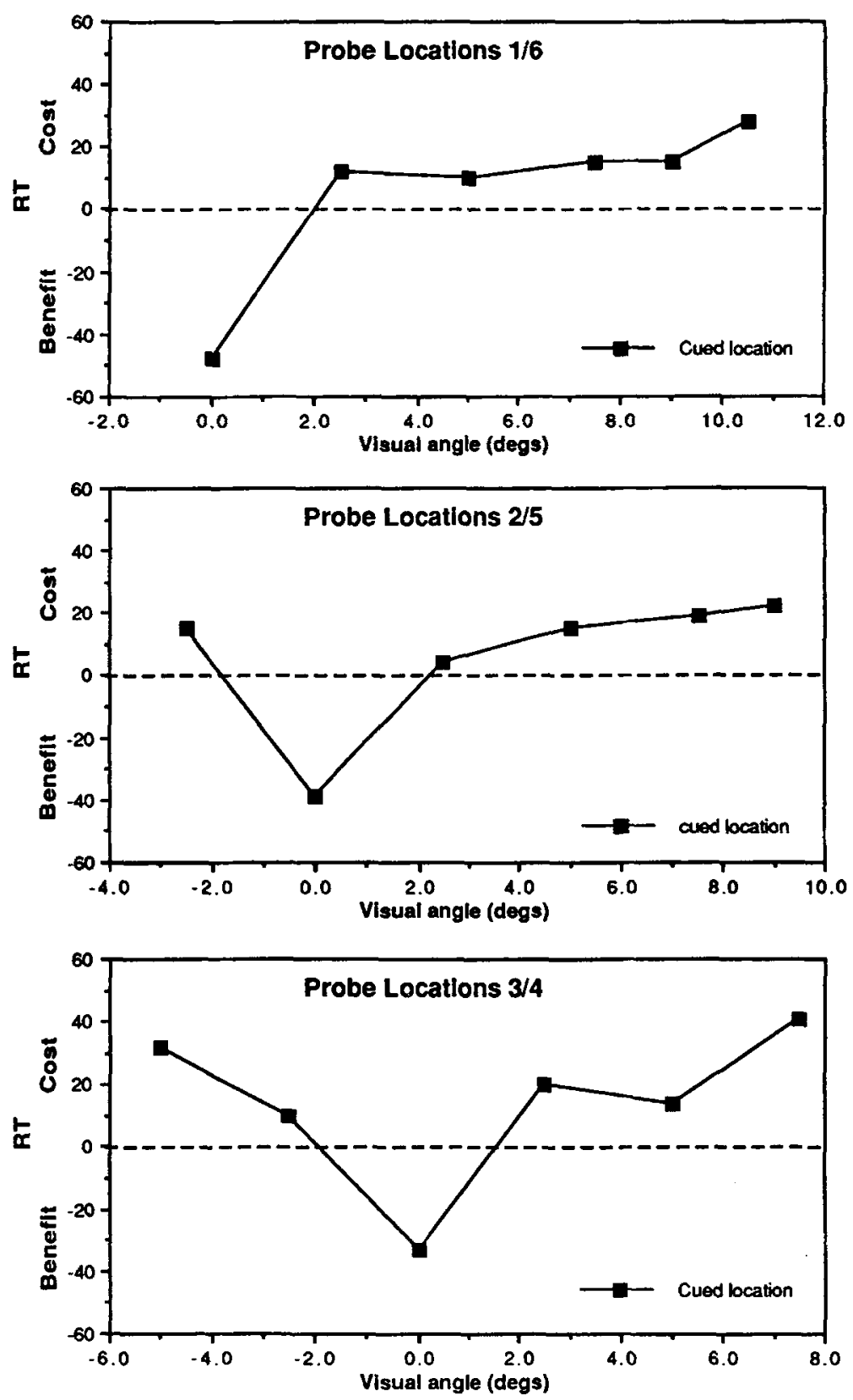

Figure 4. Reaction time (RT) distributions from Experiment 1 collapsed with respect to symmetry about the vertical meridian. RT cost/benefit is plotted as a function of the distance between cued and probed locations. On the horizontal axis, negative visual angles represent cued locations lateral to the probe, positive visual angles represent cued locations medial to the probe, and the validly cued location is represented by a visual angle of $0.0^{\circ}$. In all graphs, the vertical meridian occurs between the three left-most and three right-most locations.

Interestingly, our RT distributions showed patterns very similar to the SD distributions - a speeding of RT at the cued location and little or no attentional modulations beyond $2.5^{\circ}$. Such a pattern differs from the broader RT distributions reported previously (see, e.g., Henderson \& Macquistan, 1993; LaBerge \& Brown, 1989; Shulman et al., 1985). It should be noted, however, that while the present RT pattern bears some superficial similarity to attentional modulations in RT that span very narrow regions of visual space (see, e.g., LaBerge, 1983), most previous reports have shown that RT continues to slow with increasing cue-target separation (e.g., Henderson \& Macquistan, 1993; Shepherd \& Müller, 1989). This pattern is not seen in the present data.

A possible explanation for this discrepancy between the RT distributions reported here and those reported pre- 

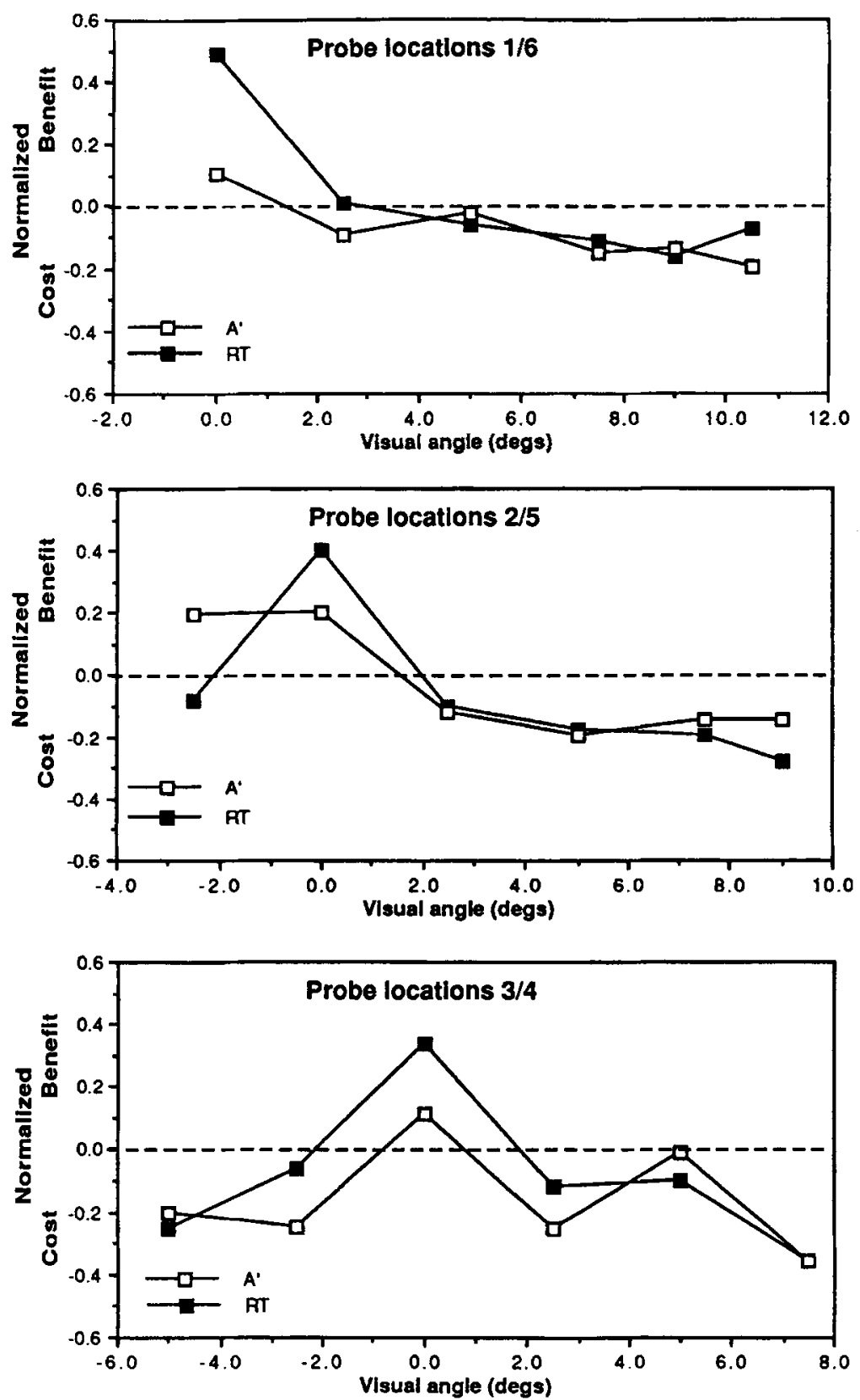

Figure 5. Comparisons between normalized $\boldsymbol{A}^{\prime}$ and reaction time (RT) distributions from Experiment 1. Because the data are normalized, benefits for RTs are now oriented up and costs for RTs are oriented down, in contrast to Figure 4.

viously may have to do with the instructions given to the subjects. In the present study, subjects were instructed to emphasize response accuracy. No emphasis was placed on overall speed of response. In contrast, studies reporting RT as a primary measure typically place strong emphasis on response times in their instructions to subjects. As a result, subjects in Experiment 1 may have adopted a strategy of focusing their attention narrowly in order to perform the task with high accuracy. Experiment 2 examines this issue.

\section{EXPERIMENT 2}

Experiment 2 was designed to see whether the instructions to subjects in Experiment 1 that emphasized response accuracy over response speed might have been responsible for the focal attentional distributions observed. Specifically, did this task component induce an attentional strategy that led to a relatively narrow spatial distribution of attention? Using the same display and luminance detection paradigm as in Experiment 1, subjects 
were again required to make a forced, two-choice decision regarding the presence/absence of a target stimulus that could occur at one of six possible locations in the upper visual hemifield. However, unlike in Experiment 1, subjects were told to respond as quickly as possible. In addition, the target stimuli employed were slightly larger than in Experiment 1.

\section{Method}

Four female subjects who had participated in Experiment 1 served as paid subjects for Experiment 2. Subjects who had participated in Experiment 1 were selected in order to permit a withinsubjects comparison of RT distributions when response emphasis (accuracy vs. speed) was varied. Experiment 2 took place approximately 2 months after Experiment 1 . All methods were identical to those of Experiment 1, except as follows. First, greater emphasis was placed on speed of response and less emphasis was placed on response accuracy. Specifically, subjects were told that response speed was now more important than response accuracy. Second, target size was increased slightly (2-3 pixels) to raise overall detection performance. Finally, only RT is reported for this experiment. ${ }^{4}$

\section{Results and Discussion}

Mean RT values as a function of cued and probed location are presented in Table 2, and the three distributions obtained by collapsing across symmetric stimulus locations are shown in Figure 6. Overall, the RTs in Experiment 2 were faster than the RTs in Experiment 1, and there was a facilitation in RT for targets at the attended location. These observations were confirmed statistically.

In order to investigate possible effects of attention location or response emphasis, three omnibus repeatedmeasures MANOVAs were performed on the distributions with attention location (six levels) and response emphasis (two levels) as factors. Significant main effects of both response emphasis [all $F \mathrm{~s}(1,6)>28.5$, all $p \mathrm{~s}<.003$ ] and attention location [all $F \mathrm{~s}(5,30)>3.30$, all $p s<.018]$ were found, but there were no significant interactions. The significant main effect of response emphasis showed that overall, RTs were quicker in Experiment 2. However, because response emphasis did not interact
Table 2

Mean Reaction Time Values (in Milliseconds) Averaged Across the 4 Subjects Who Participated in Both Experiments 1 and 2

\begin{tabular}{|c|c|c|c|c|c|c|c|}
\hline \multirow{2}{*}{$\begin{array}{l}\text { Probe } \\
\text { Location }\end{array}$} & \multicolumn{6}{|c|}{ Cue Location } & \multirow[b]{2}{*}{ Neutra } \\
\hline & 1 & 2 & 3 & 4 & 5 & 6 & \\
\hline \multicolumn{8}{|c|}{ Experiment 1} \\
\hline 1 & 437 & 491 & 507 & 551 & 461 & 505 & 504 \\
\hline 2 & 461 & 433 & 483 & 446 & 475 & 491 & 479 \\
\hline 3 & 505 & 495 & 429 & 505 & 491 & 530 & 475 \\
\hline 4 & 495 & 502 & 454 & 435 & 507 & 507 & 483 \\
\hline 5 & 517 & 508 & 493 & 457 & 435 & 502 & 479 \\
\hline 6 & 499 & 506 & 505 & 462 & 450 & 413 & 465 \\
\hline \multicolumn{8}{|c|}{ Experiment 2} \\
\hline 1 & 265 & 280 & 287 & 323 & 316 & 291 & 302 \\
\hline 2 & 271 & 264 & 297 & 279 & 302 & 294 & 284 \\
\hline 3 & 294 & 279 & 276 & 290 & 292 & 304 & 292 \\
\hline 4 & 293 & 286 & 315 & 269 & 306 & 295 & 284 \\
\hline 5 & 288 & 339 & 312 & 305 & 261 & 267 & 303 \\
\hline 6 & 283 & 284 & 302 & 311 & 292 & 257 & 293 \\
\hline
\end{tabular}

with attention location, the distribution patterns were in fact similar.

In order to see whether the effects of attention were restricted to the valid location, a second set of three repeatedmeasures MANOVAs were performed that included only the five invalid scores in each distribution (i.e., attention location as a factor with five levels). No effect of attention location was found [all $F_{\mathrm{s}}(4,12)<1.80$, all $p \mathrm{~s}>$ .19]. Thus, even when response speed was emphasized over accuracy, the RT distribution again failed to replicate the broader RT distribution patterns reported previously in the literature (e.g., Henderson \& Macquistan, 1993; Shulman et al., 1986; Shulman et al., 1985).

The results of Experiment 2 suggest that the differences between the RT distributions reported in Experiment 1 and those reported elsewhere in the literature are not due simply to an emphasis on response speed. Given that the $A^{\prime}$ and RT distributions in Experiment 1 showed similar patterns, the evidence suggests that the effects of spatial attention are similarly indexed by $A^{\prime}$ and RT mea-

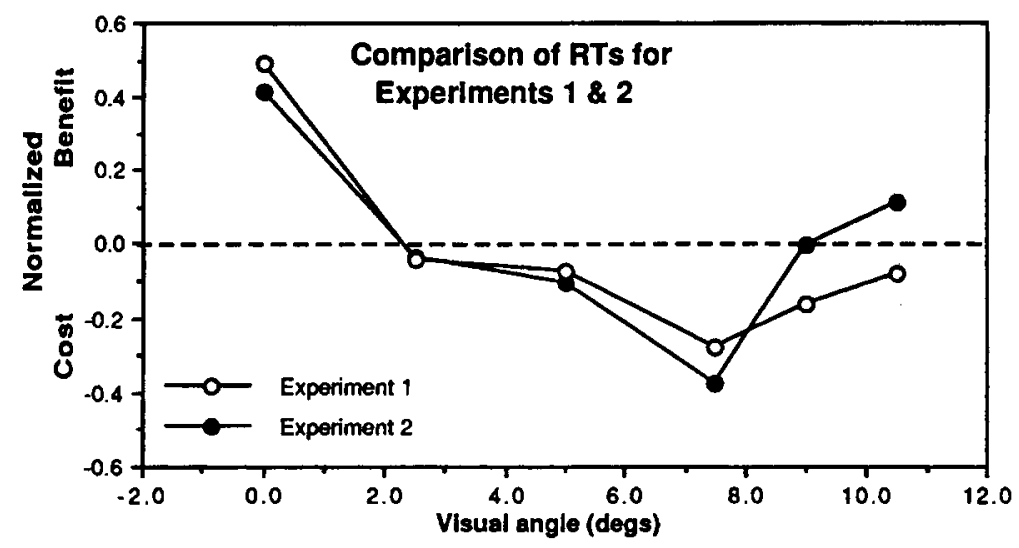

Figure 6. Comparison of fully collapsed reaction time (RT) distributions for the 4 subjects participating in both Experiment 1 (response accuracy emphasized) and Experiment 2 (response speed emphasized). 
sures in the experimental paradigm used here. Perhaps, then, the difference between the focal RT gradients reported here and the broader gradients reported elsewhere reflect differences in attentional allocation induced by the experimental paradigms employed. Specifically, difficult tasks such as detection of rapidly masked targets may require a more focal allocation of attention due to the high perceptual demands placed on the observer. On the other hand, suprathreshold RT tasks, because they are not as perceptually demanding, may allow a less-focused attentional state and thus result in broader RT distributions. Experiment 3 was performed to investigate this issue.

\section{EXPERIMENT 3}

In Experiment 3, we investigated the spatial distribution of attention in a speeded RT task. A display similar to those in Experiments 1 and 2 was used, and subjects were required to respond as quickly as possible to the onset of a target stimulus that could occur at one of six possible locations in the upper visual hemifield. However, unlike in the previous two experiments, targets were suprathreshold, were not masked, and were presented on almost every trial.

\section{Method}

Eight people ( 5 females, 3 males; 1 left-handed; age, 18-31) served as paid subjects for Experiment 3; all had normal or corrected-to-normal vision. All methods and procedures were identical to Experiments 1 and 2, except as follows. The mask used in the previous experiments was replaced with a $100-\mathrm{msec}$ blank interval. Neutral cue trials were reduced from $19 \%$ of the overall number of trials to $9.5 \%$ of the trials, and the remaining $9.5 \%$ of the trials were used as catch trials in which no target occurred. Targets, similar in size to those in Experiment 2, were thus presented on $90.5 \%$ of the trials. Stimuli were presented on an NEC 4FG color monitor driven by a 486 -based microcomputer. The six background squares were purple, and the cues, target, and fixation spot were green. Subjects used one response button, with hand of response counterbalanced between subjects. They were instructed to respond as quickly as possible to target onset, while avoiding anticipatory responses occurring prior to target onset.

\section{Results and Discussion}

Mean RT values as a function of cued and probed location are presented in Table 3 . In order to facilitate comparison between the RT gradients in Experiment 3 and the RT gradients in Experiment 1, the data in Table 3 were normalized (see the Appendix) and plotted with the RT data from Experiment 1 in Figure 7. The overall error rate on catch trials was .026 , ranging from .006 (location 4) to .057 (location 3 ) across the six cued locations. The RT distributions from Experiment 3 tend to show a facilitation in RT for targets at the cued location, as was seen in Experiments 1 and 2. However, there now appears to be a more gradual slowing in RT with increasing cuetarget distance, indicating that the facilitatory effects of attention were not limited to the cued location. Thus, the pattern differs from the results of Experiments 1 and 2. These observations were confirmed statistically.
Table 3

Mean Reaction Time Values (in Milliseconds) From Experiment 3, Averaged Across the 8 Subjects

\begin{tabular}{cccccccc}
\hline $\begin{array}{c}\text { Probe } \\
\text { Location }\end{array}$ & 1 & \multicolumn{7}{c}{ Cue Location } & \\
\hline 1 & 243 & 251 & 305 & 304 & 312 & 329 & 289 \\
2 & 261 & 240 & 268 & 284 & 311 & 320 & 265 \\
3 & 296 & 246 & 235 & 259 & 307 & 290 & 262 \\
4 & 314 & 292 & 282 & 245 & 247 & 285 & 264 \\
5 & 306 & 283 & 289 & 273 & 244 & 272 & 286 \\
6 & 325 & 317 & 327 & 293 & 269 & 244 & 298 \\
\hline
\end{tabular}

First, to investigate overall effects of attention and visual field, three omnibus repeated-measures MANOVAs were performed, with attention location (six levels) and visual field (two levels) as factors. Significant main effects of attention location were found in all three distribution pairs [all $F \mathrm{~s}(5,35)>7.32$, all $p \mathrm{~s}<.001]$. No significant main effects of visual field or interactions were found.

In order to see whether these attention effects were isolated to the valid locations, a second series of repeatedmeasures MANOVAs were performed, identical to those above except that they excluded the valid scores in each distribution (i.e., attention location was now a factor with five levels). Significant effects of attention location were found in all three MANOVAs [all $F \mathrm{~s}(4,28)>4.90$, all $p s<.005$ ]; this differed from the results of Experiments 1 and 2, where significant effects of attention location were restricted to the valid locations.

To determine how far from the valid location an effect of attention could be obtained in each distribution pair, a third series of repeated-measures MANOVAs was performed on the largest set of adjacent invalid scores in each distribution pair (i.e., the set of invalid locations to the right of the valid score in each graph in Figure 7). For each distribution pair, if a significant effect of attention was found in this initial MANOVA, the invalid score representing the shortest distance between cued and probed locations was removed from the aforementioned set of adjacent invalid scores, and the MANOVA was performed again (with attention level now reduced by one relative to the previous MANOVA). This cycle was repeated for each distribution pair until a significant effect of attention was no longer found. Results indicated that attentional effects upon RT occurred out to $5.0^{\circ}$ in the $2 / 5$ and $3 / 4$ distributions [both $F_{\mathrm{s}}(4,28)>4.90$, both $p \mathrm{~s}<.005$ ] and to $7.5^{\circ}$ in the $1 / 6$ distribution $[F(3,21)=7.07, p=$ $.002]$.

These RT patterns from Experiment 3 differed from those in Experiments 1 and 2, where attention effects were limited to within $2.5^{\circ}$ of the attended location. Thus, these broader gradients in Experiment 3 are more typical of the RT patterns reported previously (see, e.g., Downing \& Pinker, 1985; Henderson \& Macquistan, 1993; Shulman et al., 1986; Shulman et al., 1985). Our interpretations for why the RT distribution pattern in Ex- 

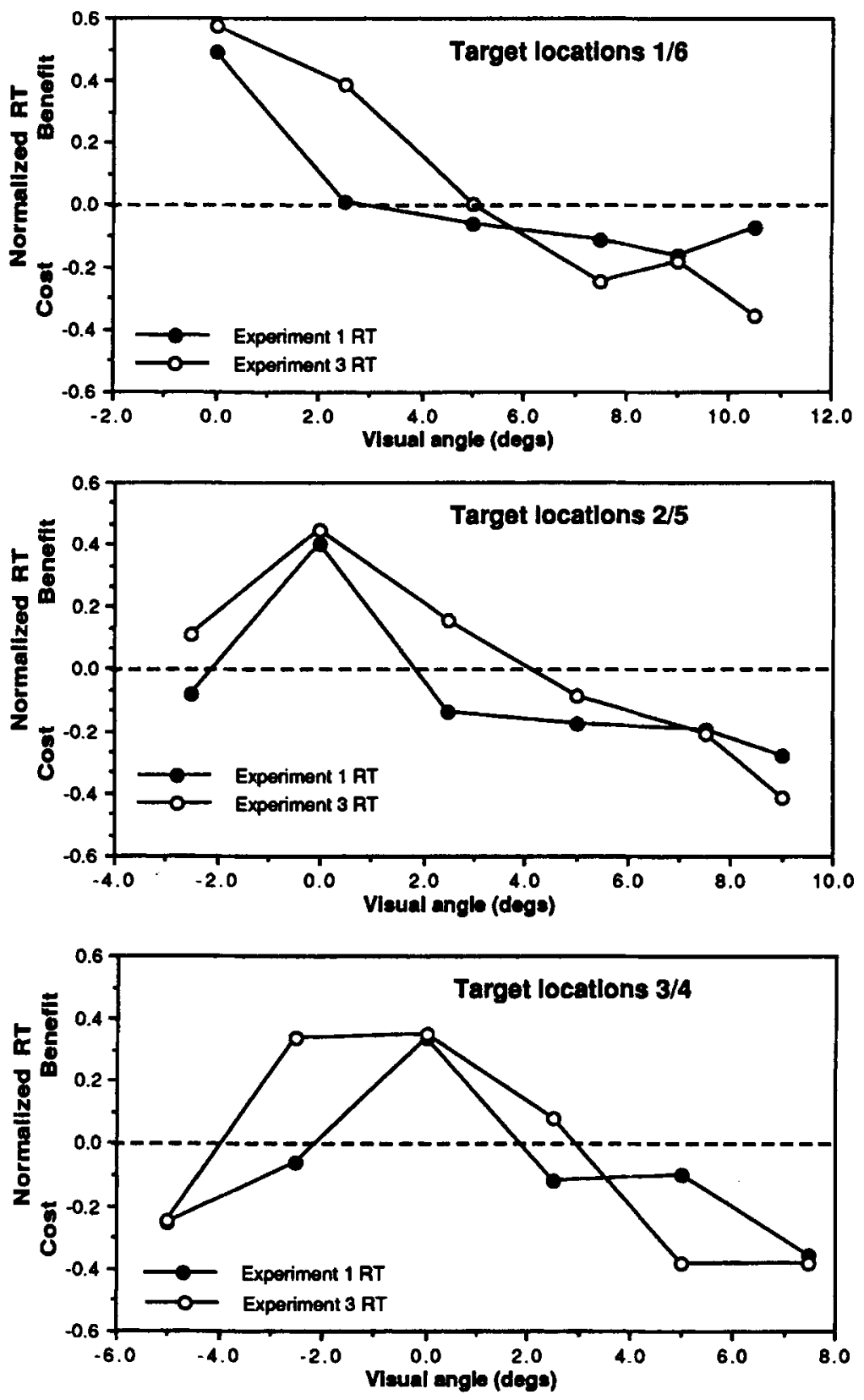

Figure 7. Comparison of reaction time (RT) distributions from Experiment 3 with RT distributions from Experiment 1. Distributions are normalized (see the Appendix) and collapsed with respect to symmetry about the vertical meridian. RT cost/benefit is plotted as a function of the distance between cue and target locations.

periment 3 differed from the RT distribution patterns in Experiments 1 and 2 are presented below.

\section{GENERAL DISCUSSION}

We investigated the spatial distribution of visual attention in an endogenous cuing paradigm, using signal detection and response latency measures. The results of Experiment 1 showed that in a threshold-level luminance detection task, attentional modulations of detection accuracy and RT were confined to within $2.5^{\circ}$ of an attended location. This relatively focal pattern replicates and extends the SD findings of Downing (1988) and Müller and Humphreys (1991) in a design that controlled for possible methodological confounds in their studies (see Hawkins et al., 1990; Luck et al., 1994). More generally, our findings also support previous research showing that visual-spatial attention can modulate perceptual sensi- 
tivity (e.g., Downing, 1988; Hawkins et al., 1990; Heinze \& Mangun, 1995; Luck et al., 1994; Mangun \& Hillyard, 1988; Müller \& Humphreys, 1991).

The focal RT pattern of Experiment 1, however, differed from prior RT findings, which have typically reported much broader RT distributions (e.g., Downing \& Pinker, 1985; Henderson \& Macquistan, 1993; Shulman et al., 1986; Shulman et al., 1985). In Experiment 2, we hypothesized that a possible factor contributing to our more focal RT pattern was the greater emphasis that our SD study placed on response accuracy than on response speed. That is, perhaps subjects would adopt a less focal attentional distribution if response speed had been emphasized, as in previous RT studies. However, the results of Experiment 2, in which response speed was emphasized, showed that although overall RT performance was significantly improved (i.e., faster), a focal RT distribution was still observed. Hence, focal RT distributions are not simply the result of an emphasis on accuracy rather than speed of response.

An alternative explanation for the focal RT distributions of Experiments 1 and 2 may be found by considering the perceptual requirements inherent in SD as opposed to RT studies. SD paradigms characteristically use thresholdlevel targets in detection or discrimination tasks, as was done in Experiments 1 and 2. This may include poststimulus masking to limit the duration of perceptual information available to the observer. In contrast, most previous RT cuing studies have used suprathreshold targets. Thus, target detectability may have been a contributing factor in producing the focal RT distributions in Experiments 1 and 2. That is, because increasing the commitment of attention to a spatial location increases the pickup of stimulus information from that location (cf. Lavie \& Tsal, 1994), as targets become less salient, allocation strategies may change, producing narrower attentional distributions. The results from Experiment 3 support this view. When suprathreshold targets were employed in a simple RT paradigm, the RT distributions were significantly broader than the RT distributions in Experiments 1 and 2 -a pattern that is consistent with the results of prior RT studies (e.g., Downing \& Pinker, 1985; Shulman et al., 1986; Shulman et al., 1985).

In sum, the evidence from our three experiments suggests that perceptual factors can influence the spatial distribution of attention. Specifically, as perceptual demands increase (e.g., via decreased target saliency), attention becomes more narrowly allocated in order to focus greater attentional resources on the expected target location. This notion of a flexible component to attentional allocation is consistent with many models of attention. For example, the "zoom-lens" theory proposed by Eriksen and colleagues (Eriksen \& St. James, 1986; Eriksen $\&$ Yeh, 1985; see also LaBerge, 1983) posits that attention may be distributed along a continuum from highresolution with a narrow focus to low-resolution with a broad focus. ${ }^{5}$ This conclusion is also consistent with the extensive literature showing that attentional allocation is affected by various stimulus and task parameters (e.g., Andersen, 1990; Andersen \& Kramer, 1993; Castiello \& Umiltá, 1992; Eriksen \& Webb, 1989; Humphreys, 1981; Kramer \& Jacobson, 1991; LaBerge, Brown, Carter, Bash, \& Hartley, 1991; Pan \& Eriksen, 1993; Podgorny \& Shepard, 1983; Yantis \& Johnston, 1990).

Alternatives exist, however, to the idea that differing allocation strategies led to differences between the distribution patterns in the present experiments. For example, if subjects set progressively higher decision/response criteria for target locations that were increasingly distant from the cued location, the result would have been a systematic slowing of RTs as a function of cue-to-target separation. This circumstance would have tended to create a broad RT gradient pattern. Such a possibility could mean that attentional modulations of perceptual sensitivity did not differ across experiments, as proposed. Rather, the broad RT gradient pattern of Experiment 3 might have reflected the contribution of later, postperceptual stages of processing.

Although the foregoing scenario is plausible, there has been no evidence from either RT or SD studies that observer bias produces gradient patterns in RT. Indeed, Müller and Humphreys (1991, Experiment 2) found that observer bias (beta) was actually slightly lower for targets more distant from the cued location, a pattern opposite to that which would be required to generate slower RTs for larger cue-to-target separations. Moreover, the experiments of Downing (1988) convincingly demonstrate that perceptual demands play a role in the spatial distribution of attention; she obtained more focal patterns in $d^{\prime}$ in form and orientation discrimination tasks than in luminance or brightness discrimination tasks. Accordingly, a flexible allocation model, driven by perceptual demands, is sufficient to explain the different attention distributions reported in the present experiments. ${ }^{6}$ In addition, this position does not require making questionable a priori assumptions about the stages of information processing indexed by SD as opposed to RT measures (for a discussion, see Müller \& Humphreys, 1991; Shulman \& Posner, 1988).

In conclusion, our data support the view that voluntary covert visual attention affects perceptual sensitivity as indexed by $A^{\prime}$ and response latency as indexed by RT. Our findings also strongly suggest that perceptual demands affect the manner in which subjects distribute their attention within the visual field. This implies that the focal SD and the somewhat broader RT distributions reported previously in the literature may have reflected allocation strategies adopted by subjects in order to conform to the specific perceptual requirements of the situation at hand.

\section{REFERENCES}

Andersen, G. J. (1990). Focused attention in three-dimensional space. Perception \& Psychophysics, 47, 112-120.

ANDERSEN, G. J., \& Kramer, A. F. (1993). Limits of focused attention in three-dimensional space. Perception \& Psychophysics, 53, 658-667. 
BASHINSKI, H. S., \& BACHARACH, V. R. (1980). Enhancement of perceptual sensitivity as the result of selectively attending to spatial locations. Perception \& Psychophysics, 28, 241-248.

Castiello, U., \& Umiltá, C. (1992). Splitting focal attention. Journal of Experimental Psychology: Human Perception \& Performance, $18,837-848$.

CraIG, A. (1979). Nonparametric measures of sensory efficiency for sustained monitoring tasks. Human Factors, 21, 69-78.

DowNING, C. J. (1988). Expectancy and visuo-spatial attention: Effects on perceptual quality. Journal of Experimental Psychology: Human Perception \& Performance, 13, 228-241.

Downing, C. J., \& Pinker, S. (1985). The spatial structure of visual attention. In M. I. Posner \& O. S. M. Marin (Eds.), Attention and performance $X I$ (pp. 171-188). Hillsdale, NJ: Erlbaum.

EGLY, R., \& HoMA, D. (1991). Reallocation of visual attention. Journal of Experimental Psychology: Human Perception \& Performance, 17, 142-159.

Eriksen, C. W., \& St. James, J. D. (1986). Visual attention within and around the field of focal attention: A zoom lens model. Perception \& Psychophysics, 40, 225-240.

Eriksen, C. W., \& WeBb, J. M. (1989). Shifting of attentional focus within and about a visual display. Perception \& Psychophysics, 45, 175-183.

ERIKSEN, C. W., \& YEH, Y.-Y. (1985). Allocation of attention in the visual field. Journal of Experimental Psychology: Human Perception \& Performance, 11, 583-597.

Green, D., \& Swets, J. (1966). Signal detection theory and psychophysics. New York: Wiley.

Hawkins, H. L., Hillyard, S. A., Luck, S. J., Mouloua, M., DownING, C. J., \& WoodWARD, D. P. (1990). Visual attention modulates signal detectability. Journal of Experimental Psychology: Human Perception \& Performance, 16, 802-811.

Heinze, H.-J., Luck, S. J., MünTE, T. F., Gös, A., Mangun, G. R., \& HILlYARD, S. A. (1994). Attention to adjacent and separate positions in space: An electrophysiological analysis. Perception \& Psychophysics, 56, 42-52.

HeINZE, H.-J., \& MANGUN, G. R. (1995). Electrophysiological signs of sustained and transient attention to spatial locations. Neuropsychologia, 33, 889-908.

Heinze, H.-J., Mangun, G. R., Burchert, W., Hinrichs, H., Scholz, M., Münte, T. F., Gös, A., Scherg, M., Johannes, S., Hundeshagen, H., Gazzaniga, M. S., \& Hillyard, S. A. (1994). Combined spatial and temporal imaging of brain activity during visual selective attention in humans. Nature, 372, 543-546.

Henderson, J. M. (1991). Stimulus discrimination following covert attentional orienting to an exogenous cue. Journal of Experimental Psychology: Human Perception \& Performance, 17, 91-106.

Henderson, J. M., \& Macquistan, A. D. (1993). The spatial distribution of attention following an exogenous cue. Perception \& Psychophysics, 53, 221-230.

Hodgson, T. L., Müller, H. J., \& O'Leary, M. J. (1996). Attentional localization prior to simple and directed manual responses. Manuscript submitted for publication.

HumpHREYs, G. W. (1981). On varying the span of visual attention: Evidence for two modes of spatial attention. Quarterly Journal of Experimental Psychology, 33A, 17-31.

Klein, R., Kingstone, A., \& Pontefract, A. (1992). Orienting of visual attention. In K. Rayner (Ed.), Eye movements and visual cognition: Scene perception and reading (pp. 46-63). Amsterdam: Elsevier, North-Holland.

KLEIN, R., \& MCCORMICK, P. (1989). Covert visual orienting: Hemifieldactivation can be mimicked by zoom lens and midlocation placement strategies. Acta Psychologica, 70, 235-250.

KRAMER, A. F., \& JaCOBSON, A. (1991). Perceptual organization and focused attention: The role of objects and proximity in visual processing. Perception \& Psychophysics, 50, 267-284

LABERGE, D. (1983). Spatial extent of attention to letters and words. Journal of Experimental Psychology: Human Perception \& Performance, 9, 371-379.

LABERGE, D., \& BRown, V. (1986). Variations in size of the visual field in which targets are presented: An attentional range effect. Perception \& Psychophysics, 40, 188-200.
LABERGE, D., \& Brown, V. (1989). Theory of attentional operations in shape identification. Psychological Review, 96, 101-124.

LaBerge, D., Brown, V., Carter, M., Bash, D., \& Hartley, A. (1991). Reducing the effects of adjacent distracters by narrowing attention. Journal of Experimental Psychology: Human Perception \& Performance, 17, 65-76.

Lavie, N., \& Tsal, Y. (1994). Perceptual load as a major determinant of the locus of selection in visual attention. Perception \& Psychophysics, 56, 183-197.

Luck, S. J., Hillyard, S. A., Mouloua, M., Woldorf,, M. G., Clark, V. P., \& Hawkins, H. L. (1994). Effects of spatial cuing on luminance detectability: Psychophysical and electrophysiological evidence for early selection. Journal of Experimental Psychology: Human Perception \& Performance, 20, 887-904.

Mangun, G. R., \& Hillyard, S. A. (1987). The spatial allocation of visual attention as indexed by event-related brain potentials. Human Factors, 29, 195-212.

Mangun, G. R., \& Hillyard, S. A. (1988). Spatial gradients of visual attention: Behavioral and electrophysiological evidence. Electroencephalography \& Clinical Neurophysiology, 70, 417-428.

ManGUN, G. R., \& Hillyard, S. A. (1991). Modulations of sensoryevoked brain potentials indicate changes in perceptual processing during visual-spatial priming. Journal of Experimental Psychology: Human Perception \& Performance, 17, 1057-1074.

Mangun, G. R., Plager, R., Loftus, W., Hillyard, S. A., Luck, S. J., Handy, T. C., Clark, V. P., \& Gazzaniga, M. S. (1994). Monitoring the visual world: Hemispheric asymmetries and subcortical processes in attention. Journal of Cognitive Neuroscience, 6, 267-275.

MiLLER, J. (1991). The flanker compatibility effect as a function of visual angle, attentional focus, visual transients, and perceptual load: A search for boundary conditions. Perception \& Psychophysics, 49, 270-288.

Müller, H. J., \& FindlaY, J. M. (1987). Sensitivity and criterion effects in the spatial cuing of visual attention. Perception \& Psychophysics, 42, 383-399.

MülleR, H. J., \& Humphreys, G. W. (1991). Luminance-increment detection: Capacity-limited or not? Journal of Experimental Psychology: Human Perception \& Performance, 17, 107-124.

PAN, K., \& ERIKSEN, C. W. (1993). Attentional distribution in the visual field during same-different judgments as assessed by response competition. Perception \& Psychophysics, 53, 134-144.

Podgorny, P., \& Shepard, R. N. (1983). Distribution of visual attention over space. Journal of Experimental Psychology: Human Perception \& Performance, 9, 380-393.

Pollack, I., \& Norman, D. A. (1964). A non-parametric analysis of recognition experiments. Psychonomic Science, 1, 125-126.

Posner, M. I. (1978). Chronometric explorations of mind. Hillsdale, NJ: Erlbaum.

POSNER, M. I. (1980). Orienting of attention. Quarterly Journal of Experimental Psychology, 32, 3-25.

Posner, M. I., SNyder, C. R. R., \& Davidson, B. J. (1980). Attention and the detection of signals. Journal of Experimental Psychology: General, 109, 160-174.

Previc, F. H., \& Blume, J. L. (1993). Visual search asymmetries in three-dimensional space. Vision Research, 33, 2697-2704.

Reuter-Lorenz, P. A., Kinsbourne, M., \& Moscovitch, M. (1990). Hemispheric control of spatial attention. Brain \& Cognition, 12 , 240-266.

SANTEe, J. L., \& EgETh, H. E. (1982). Do reaction time and accuracy measure the same aspects of letter recognition? Journal of Experimental Psychology: Human Perception \& Performance, 8, 489-501.

SHAW, M. L. (1984). Division of attention among spatial locations: A fundamental difference between detection of letters and detection of luminance increments. In H. Bouma \& D. G. Bouwhuis (Eds.), Attention and performance $X$ : Control of language processes ( $\mathrm{pp} .109-$ 121). Hillsdale, NJ: Erlbaum

SHEPHERd, M., \& MüLLER, H. J. (1989). Movement versus focusing of visual attention. Perception \& Psychophysics, 46, 146-154.

ShiU, L., \& PAshler, H. (1994). Negligible effect of spatial precuing on identification of single digits. Journal of Experimental Psychology: Human Perception \& Performance, 20, 1037-1054.

SHULMAN, G. L., \& POSNER, M. I. (1988). Relating sensitivity and cri- 
terion effects to the internal mechanisms of visual spatial attention. (Tech. Rep. No. 88-2). Washington, DC: Office of Naval Research. Shulman, G. L., Sheehy, J. B., \& Wilson, J. (1986). Gradients of spatial attention. Acta Psychologica, 61, 167-181.

Shulman, G. L., Wilson, J., \& Sheeny, J. B. (1985). Spatial determinants of the distribution of attention. Perception \& Psychophysics, 37, 59-65.

SPERLING, G. (1984). A unified theory of attention and signal detection. In R. Parasuraman \& D. R. Davies (Eds.), Varieties of attention (pp. 103-181). Orlando, FL: Academic Press.

SPERLING, G., \& Dosher, B. A. (1986). Strategy and optimization in human information processing. In K. R. Boff, L. Kaufman, \& J. P. Thomas (Eds.), Handbook of perception and human performance (Vol. 1, pp. 2.1-2.65). New York: Wiley.

Tassinari, G., Agliotı, S., Chelazzi, L., Marzi, C. A., \& Berluc$\mathrm{CHI}, \mathrm{G}$. (1987). Distribution in the visual field of the costs of voluntarily allocated attention and of the inhibitory after-effects of covert orienting. Neuropsychologia, 25, 55-71.

TSAL, Y. (1983). Movements of attention across the visual field. Journal of Experimental Psychology: Human Perception \& Performance, 9, 523-530.

TsaL, Y. (1989). Attending to horizontal, diagonal, and vertical positions in space. Bulletin of the Psychonomic Society, 27, 133-134.

YANTIS, S., \& Johnston, J. C. (1990). On the locus of visual selection: Evidence from focused attention tasks. Journal of Experimental Psychology: Human Perception \& Performance, 16, 135-149.

\section{NOTES}

1. "Probe-constant" distributions (the rows in Table 1) were used because the physical stimuli (i.e., probe and target) remain at a constant location, and differences in response scores within distributions are thus directly attributable to variations in the location of attention. Distributions could also be defined, however, by holding attention location constant and varying the probed location. These "attention-constant" distributions (the columns in Table I) were considered less favorable for analysis because with probe location varied, differences in response performance within distributions could be due to topographical asymmetries in retinal and cortical representations of visual space. Nevertheless, in order to more fully examine possible gradients within the data, attention-constant distributions were also analyzed. Statistics were performed on the attention-constant distributions paralleling those described for probe-constant distributions in the Response Accuracy and Reaction Times sections of the Experiment 1 Results. These results did not differ from those found for the probe-constant distributions. As a consequence, no further analyses were performed on the attention-constant distributions.

2. We also calculated $d^{\prime}$ scores for these data. However, because of the small number of trials ( 13 with a target, 13 without a target) in each invalid condition, there were instances for each subject of 1.0 hit rates and $0.0 \mathrm{FA}$ rates. Because, unlike for $A^{\prime}$, calculating $d^{\prime}$ and beta requires hit rates less than 1.0 and FA rates greater than 0.0 , two different methods of correcting for these rates were employed. The first method involved computing an average hit or false alarm rate for the given cue-target distance (collapsed across all distributions) and then multiplying that rate by the actual number of either possible hits or possible FAs for the specific location. Analysis of $d^{\prime}$ distributions derived with this correction were consistent with the results reported above for $A^{\prime}$. In addition, no significant attention effects on beta were obtained, indicating that no shifts in decision criteria occurred between cued and uncued locations. A second, more conservative, correction procedure was then used to provide comparison data. In this procedure, 1 was divided by the number of either possible hits or possible FAs, and the en- suing fraction was either used as the FA rate or subtracted from it to produce the hit rate. Although overall attention effects were lower with this correction procedure (than with the first correction method), analysis of $d^{\prime}$ distributions were also consistent with the results reported above for $A^{\prime}$. Analysis of the corresponding beta values indicated that there was, however, a significant criteria shift in the $2 / 5$ distribution pair associated with the one invalid location to the left of the valid location in the middle graph of Figure 3.

3. Linear regression analysis indicated that the RT distribution associated with the Probe 5 location showed a significant trend across the four contiguous invalid locations in the distribution. This indicates that the average slope across those locations was not.zero. However, the pattern of the entire distribution (as well as all the RT distributions in general) is still characteristic of a large drop-off out to the first invalid location and relatively little change beyond that distance. We thank an anonymous reviewer for helping to clarify this issue.

4. Initial analyses of $A^{\prime}$ data for Experiment 2 indicated significant cuing effects only in the $2 / 5$ distributions. However, accuracy performance across conditions was at or near ceiling levels, reducing the likelihood of obtaining significant cuing results with SD measures. Thus, $A^{\prime}$ was not considered further.

5. Evidence from recent electrophysiological studies suggests that these effects can be mediated by changes in perceptual processing at the level of the extrastriate visual cortex in humans (Heinze, Luck, et al., 1994; Heinze, Mangun, et al., 1994).

6. Recent unpublished evidence by Hodgson, Müller, and O'Leary suggests that during peripheral (exogenous) cuing of locations, responserelated effects may result in gradient-like RT patterns for suprathreshold stimuli. Such an explanation may be consistent with the results of Experiment 3, although endogenous cuing methods were used. We thank Hermann Müller for pointing out these interesting data.

\section{APPENDRX}

Because no effects of visual field were found, symmetric distribution pairs were first collapsed for each subject, reducing the number of distributions from six to three. Data values for each location were then normalized separately for each subject. Specifically, the highest of the six values for each of the three collapsed distributions (maximum $A^{\prime}$ or minimum RT) was set at 1.0. Likewise, the lowest value (minimum $A^{\prime}$ or maximum RT) was set at 0.0 . All four remaining points in between these minima and maxima. were then normalized by dividing the difference between the given value and the minimum by the difference between the maximum and minimum. The normalized values were then represented as costs and benefits by subtracting the normalized neutral value. Consequently, within each subject, the distribution still represents values with 1.0 between the minimum and maximum, with costs represented by negative values and benefits by positive values. This data transformation preserves the shape or trend of within-subjects distributions while eliminating between-subjects and betweenmeasures variations in the amplitude of the response (i.e., how quick or how accurate the response was). Following this procedure, the values were then averaged across subjects for each of the three distributions.

(Manuscript received February 8, 1995; revision accepted for publication September 17, 1995.) 